\title{
The Operation of the Tevatron Vacuum system
}

\author{
Authors \\ David Augustine \\ Alex Chen \\ Scott McCormick
}

This manuscript has been authored by Fermi Research Alliance, LLC under Contract No. DE-AC02-07CH11359 with the U.S. Department of Energy, Office of Science, 


\section{Outline}

- Tevatron overview and some history

- Vacuum upgrades

- Cryogenic upgrades

- Maintenance and records

- Vacuum diagnostics

- Failures

- Lessons Learned 


\section{Fermilab Site Overview}

- Fermilab-Accelerator Chain for Collider Experiments

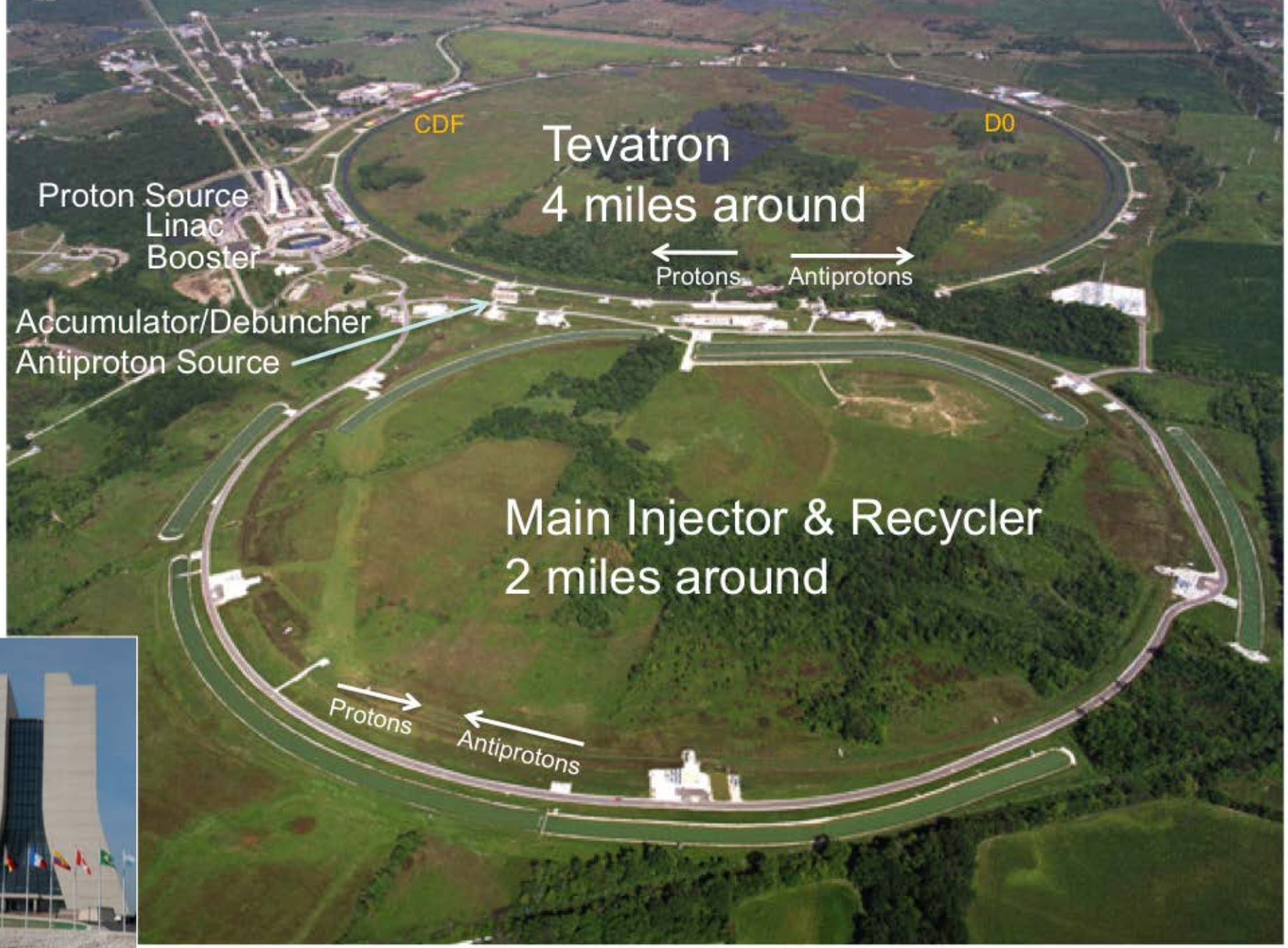




\section{The Tevatron contains}

- 24 Cryogenic loops.

- 48 Insulating vacuum systems

- 24 Cryogenic beam vacuum systems

- 29 Major and minor warm straights

- A cornucopia of gauges, valves, mechanical pumps, ion pumps, titanium sublimation pumps, and NEG 
The Tevatron is installed under the original Main Ring Accelerator

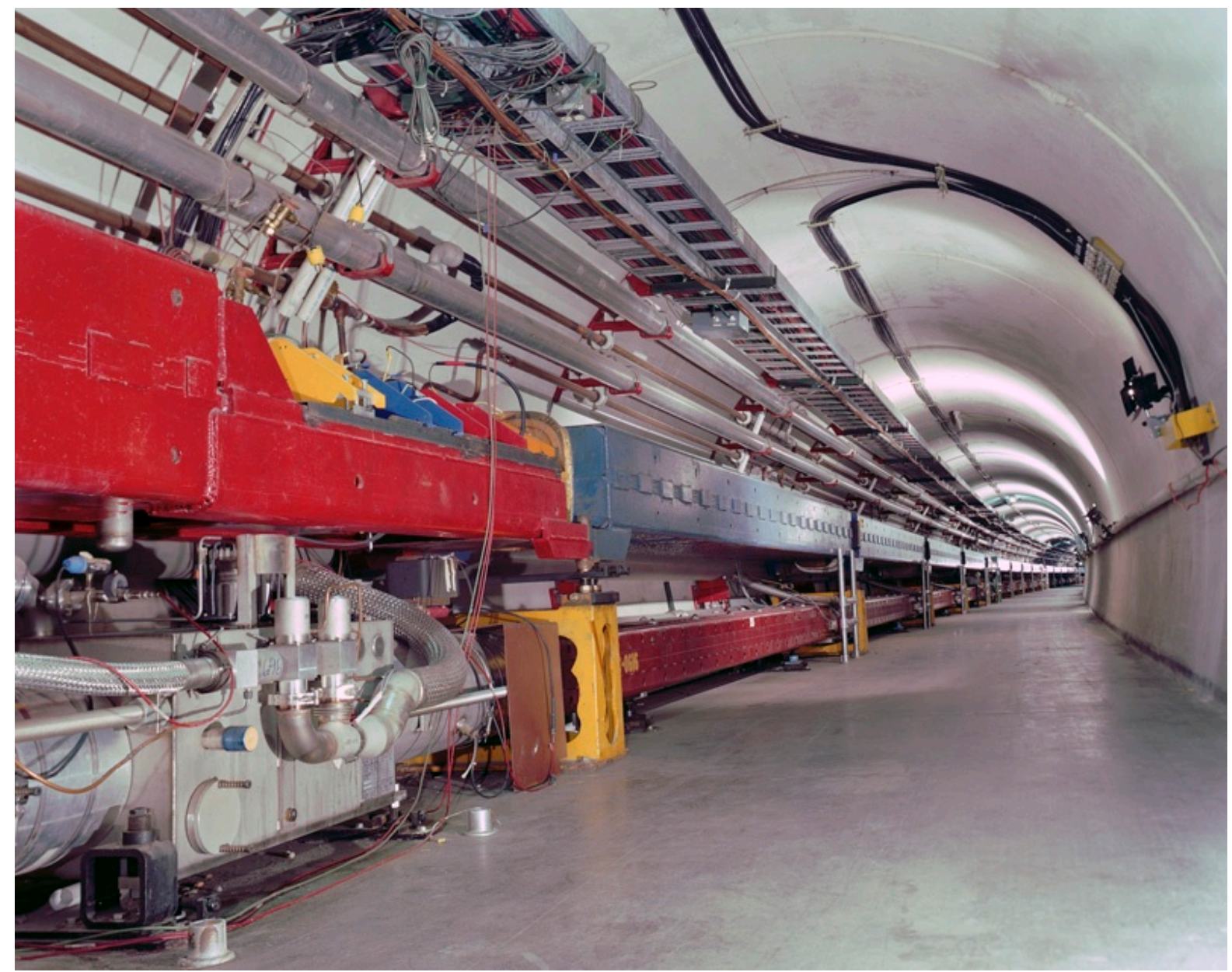




\section{Some history}

- Originally Tevatron operated in fixed target mode

- Vacuum in warm insertion points was $10^{-8}$ Torr

- Insulating vacuum was $10^{-4}$ to $10^{-8}$ Torr

- Cryogenic temperature was 4 to $4.5 \mathrm{~K}$ 


\section{Cryogenic and vacuum upgrades}

- Cryogenic system was upgraded

- Magnets now operate colder which allows higher current on buss without quenching

- Warm vacuum insertion points were upgraded

- Better choice of materials

- Improved cleaning technique

- Vacuum baking

- Reduced beam scattering due to poor vacuum 


\section{Tevatron Superconducting Dipole}

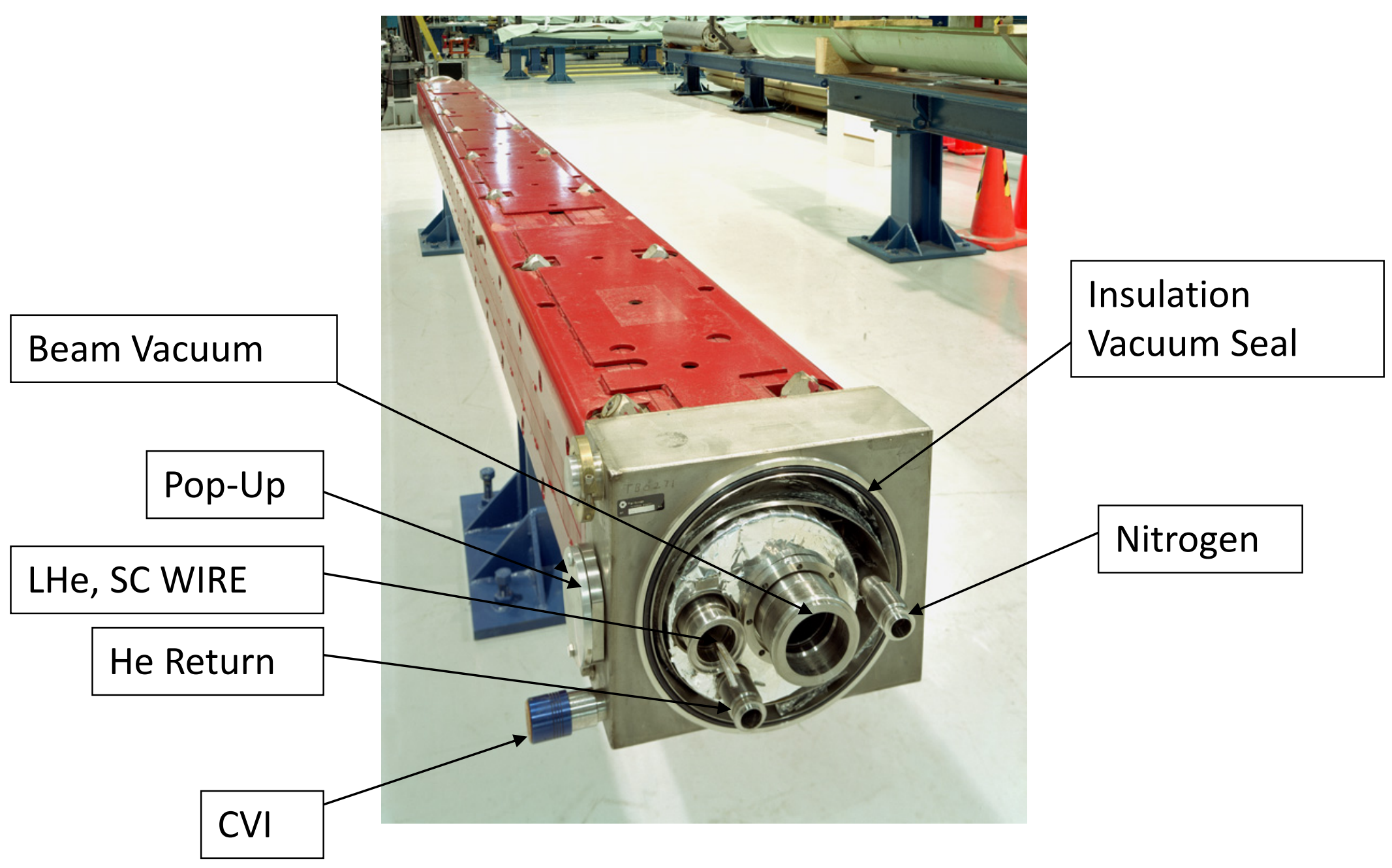




\section{Cryogenic Beam Vacuum System}

- No elastomers between the beam vacuum and atmosphere

- Ion pumps various types, area dependent

- Seals are all metal

- Gauges are thermocouple, cold cathode, and ion

- Vacuum pump out valves are all metal

- Isolation valves are metal sealed on the outside but o-ring sealed on the gate 


\section{Warm Beam Vacuum}

- No elastomers between beam vacuum and atmosphere

- System mostly electro-polished stainless steel or ceramic

- Non metal objects are measured for out gas rate prior to installation

- Many objects vacuum baked in situ

- Electrostatic separator areas have all metal gate valves 


\section{Cryogenic Insulating Vacuum system}

- One turbo molecular and roughing pump every 450 feet

- Vacuum breaks every 100 feet with isolation valves

- EPDM (Ethylene Propylene) o-rings specified

- Almost everything on the insulating vacuum system is sealed with o-rings 


\section{Maintenance records}

- Then

- Originally all installations and repairs entered into paper log books

- Information difficult to find

- Now

- All log books are web driven databases

- Most accessible and editable outside of the Main Control Room

- Electronic work list for work on operational equipment 


\section{Tevatron E-Log Maintenance entry}

\begin{tabular}{|c|c|c|c|c|c|c|c|c|c|c|c|c|}
\hline Start Studies & Make Entry & End Studies & Prev & Next & Latest & Contents & Search & Add Graph & Fix List & MCR Elog & Machine Logs & Archive \\
\hline & & & & & \multicolumn{4}{|c|}{ HomePage } & & & & \\
\hline & & & & \multicolumn{5}{|c|}{$\begin{array}{c}\text { Tevatron E-Log } 2011 \text { 17:27:17 Tue May } 312011 \\
\text {-- Shot setup for store 8784 -- }\end{array}$} & & & & \\
\hline & & & & \multicolumn{3}{|c|}{ MemoPad } & tom & & & & & \\
\hline
\end{tabular}

Studiers: Sequencer

Start of Studies Notes:
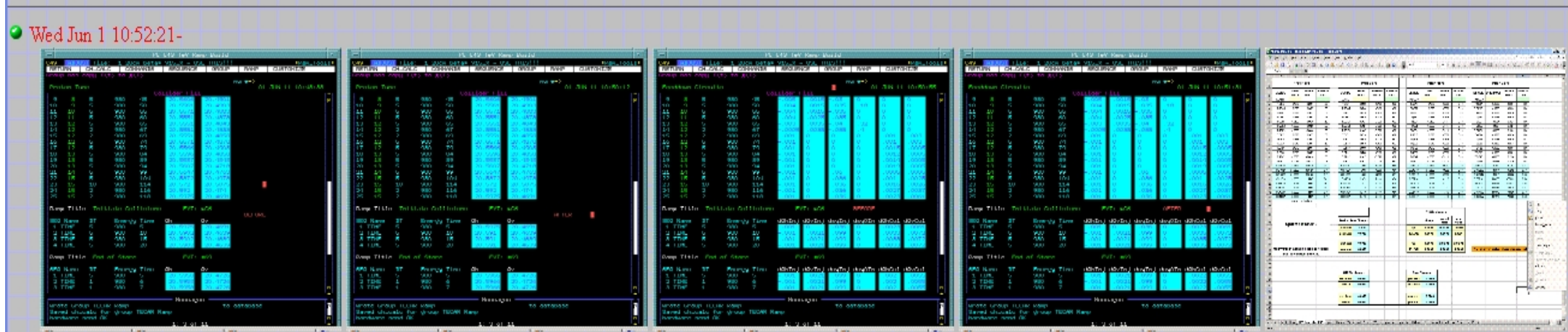

$-\mathrm{xz}, \mathrm{bh}$

-Wed Jun 1 10:53:04 comment by...xz,bh -- Tables showing the change to proton horizontal tune of +.001 at collisions

- Wed Jun 1 10:54:44- We lowered the Tev injection energy from 150.11 to 150.10 in order to reduce synchrotron oscillations at injection. - xz,bh

- Wed Jun 1 16:53:10- Inspected TEL2 A-11 and A-12 Turbo carts OK, A-1 helium background E-9, A-2 helium background E-9. TEL2 helium background 3.5 E-5. No outside air leaks found at TEL2, A-1 or A-12. Turbo cart replaced at TEL 2 because of age. Ref. Scott McCormick - James Williams

- Fri Jun 3 07:37:55 comment by...Bob Steinberg -- Access to A-E and Transfer Hall. In addition to above entry techs Sali Sylejmani and James Williams installed turbo cart JF-1 on TEL-2. Techs Bob Steinberg and Bill Dymond changed out turbo stations at B-37 and A-47 locations. B37: Rougher out \#32385, Turbo out \#34972, Rougher in \#41622, Turbo in \#34932. A47: Rougher out \#099403476 Edwards 18, Turbo out \#39152, Rougher in \#35940, Turbo in \#34962. Also did small solenoid work in E0 to help re-open valves after compressor/air loss. Supervisor Scott McCormick. 


\section{Electronic Work List}

Work Request

$*^{*}$ - indicates required field

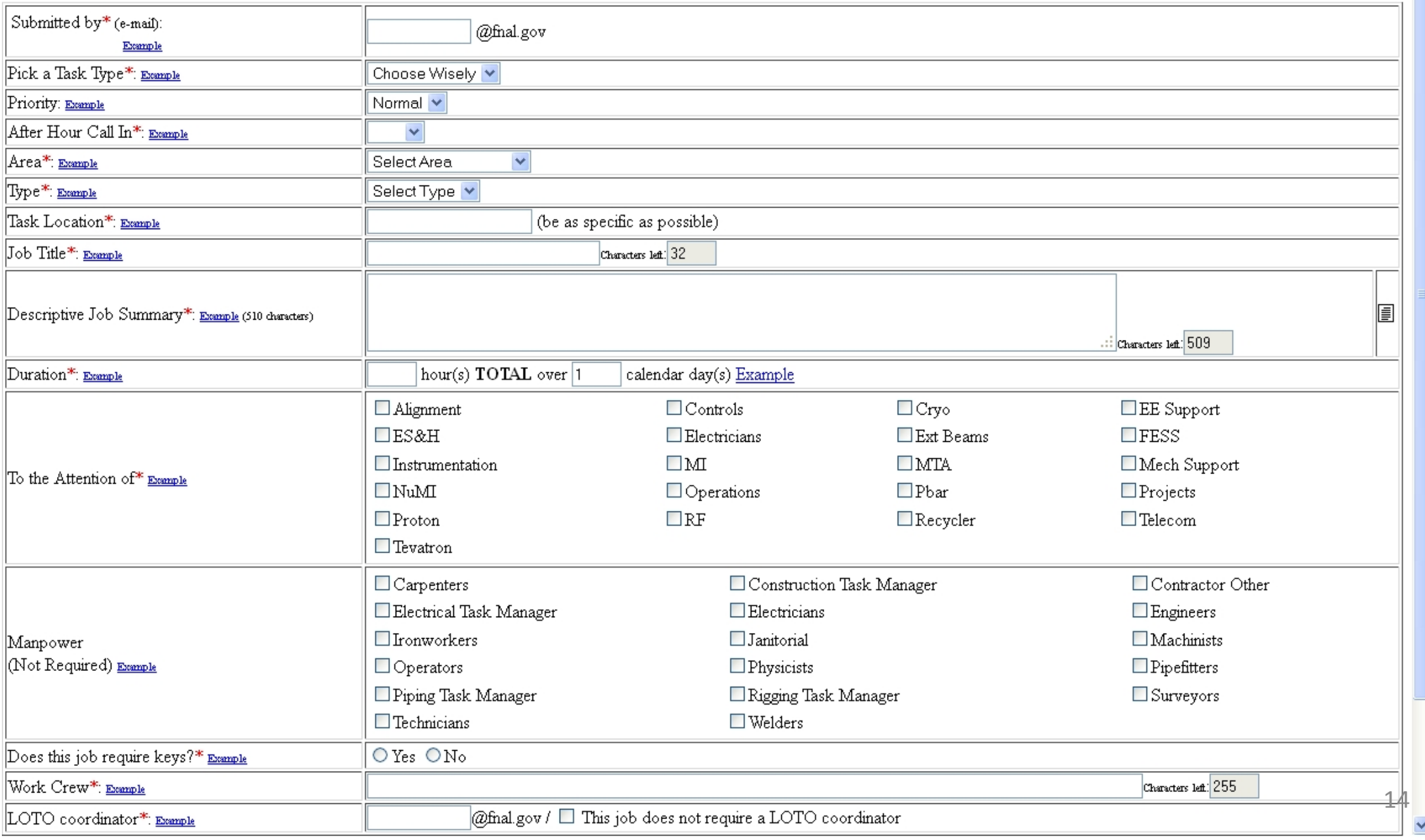




\section{Vacuum remote readouts}

- Then

- Limited remote control of vacuum hardware

- Limited ability to data log past history of an individual device

- Now

- Lots of computing power to data log thousands of devices

- Vacuum read out and control pages readily accessible 


\section{An example of a Tevatron Vacuum page, house A-2 ACNET driven}

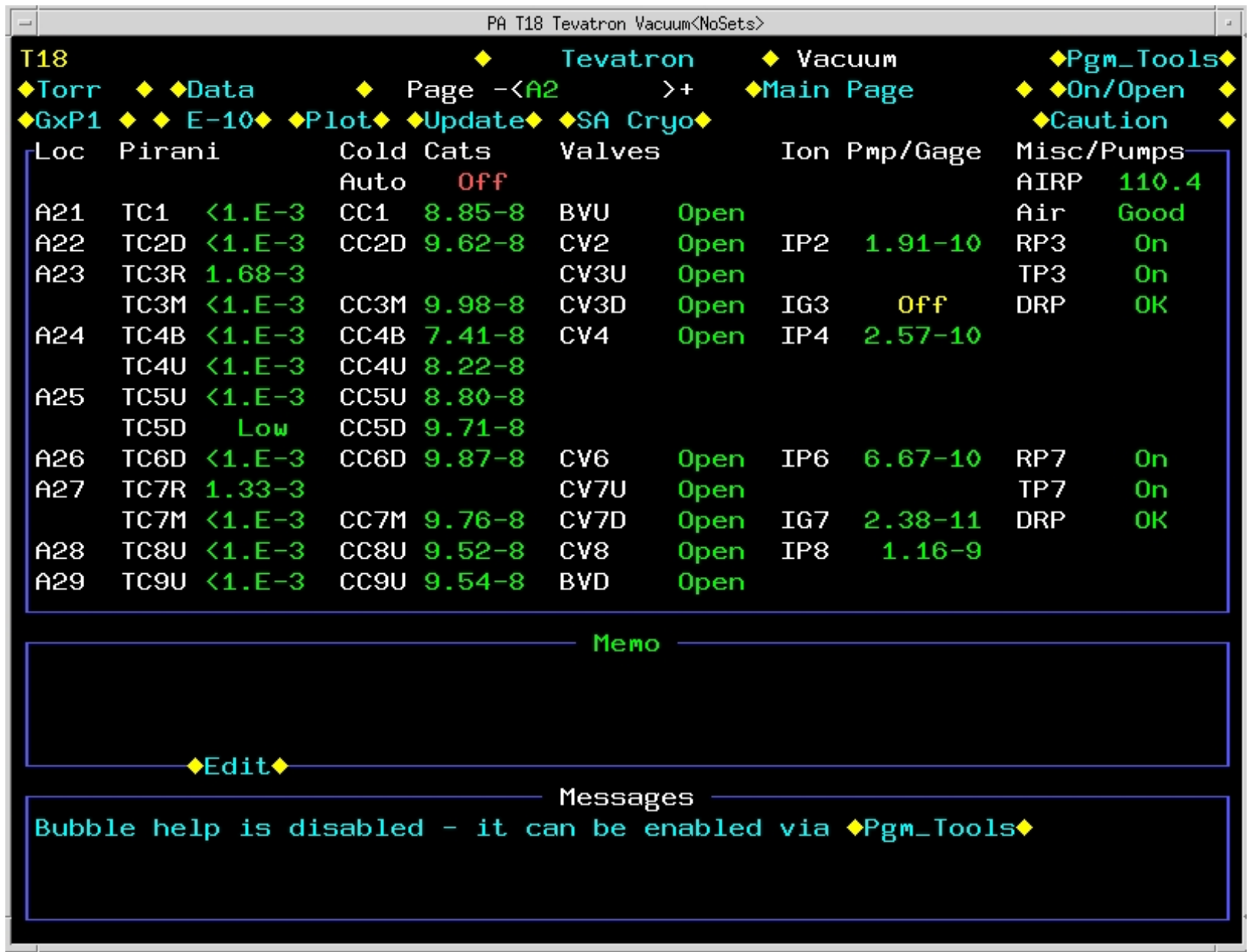




\section{An Example: Vacuum and Cryo @E4}

File View Help

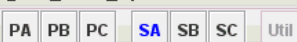

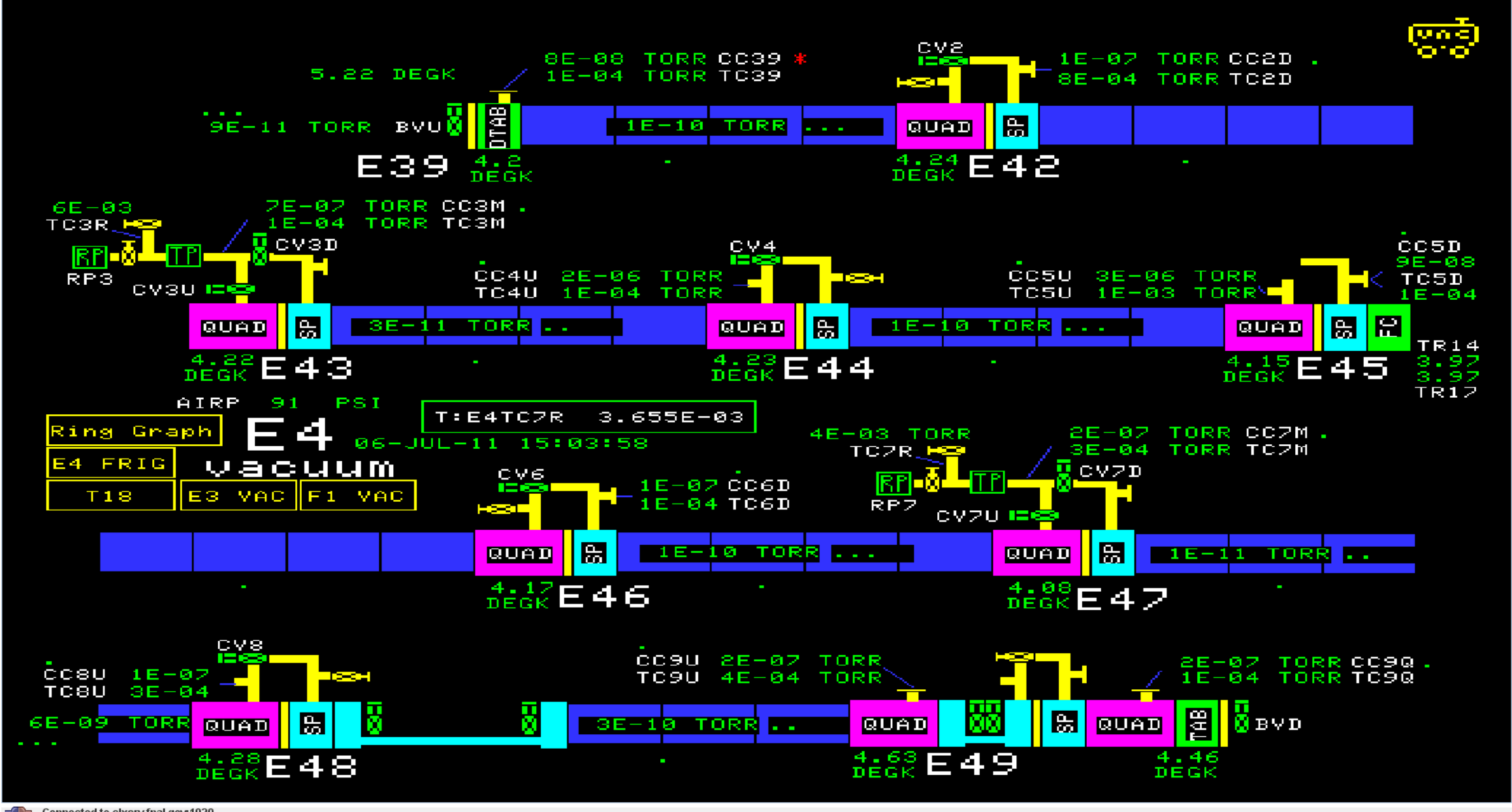




\section{An Example of Diagnosis}

File View Help

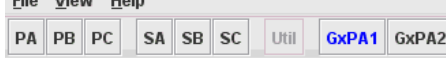

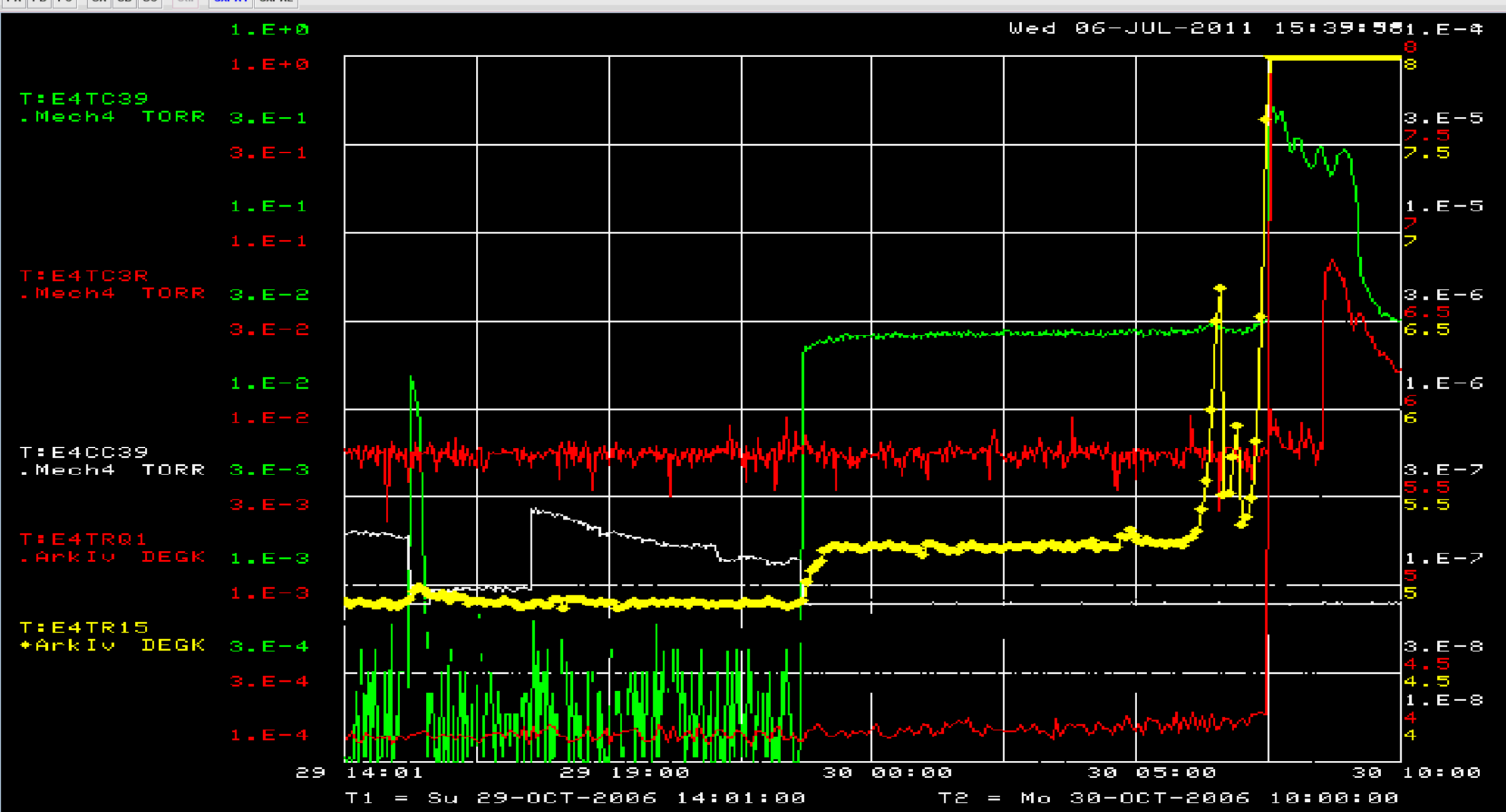




\section{Failures}

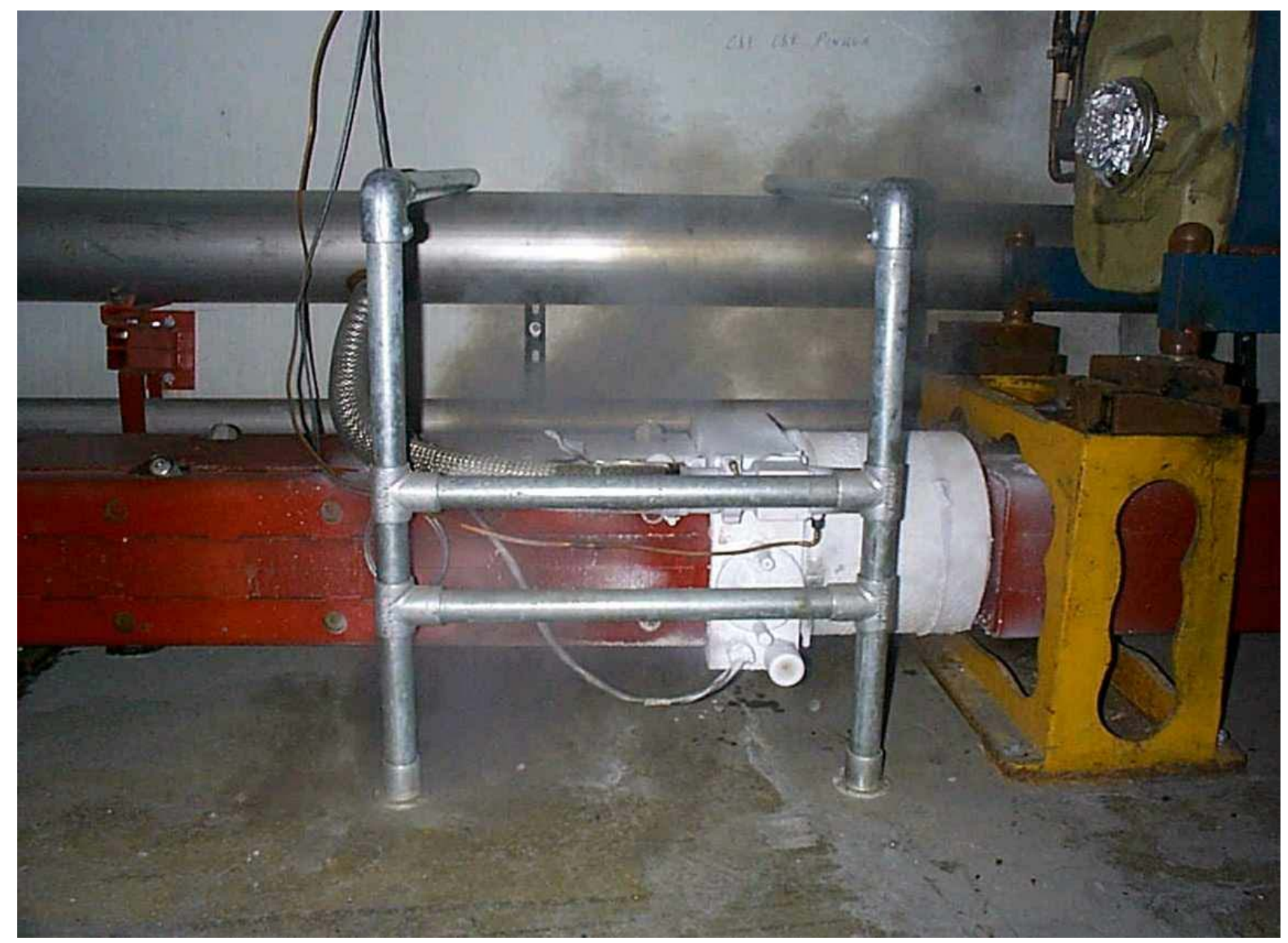




\section{Tevatron repair}

- Normal cryoloop

- Seven days cold to cold with around the clock shifts

- Low Beta cryoloop

- 12 days cold to cold with around the clock shifts 


\section{Typical Repair Routine}

- During Warmup

- Crews assigned

- Insulating vacuum spoiled to assist warmup

- Spares selected and tested

- Equipment stationed in tunnel

- When Warm

- Insulating vacuum pumped out

- Insulating vacuum leak checked first

- Cryogenic circuits leak checked next

- Sometimes damage obvious ie a 4000 amp ground fault 


\section{Ground Faulted magnet}

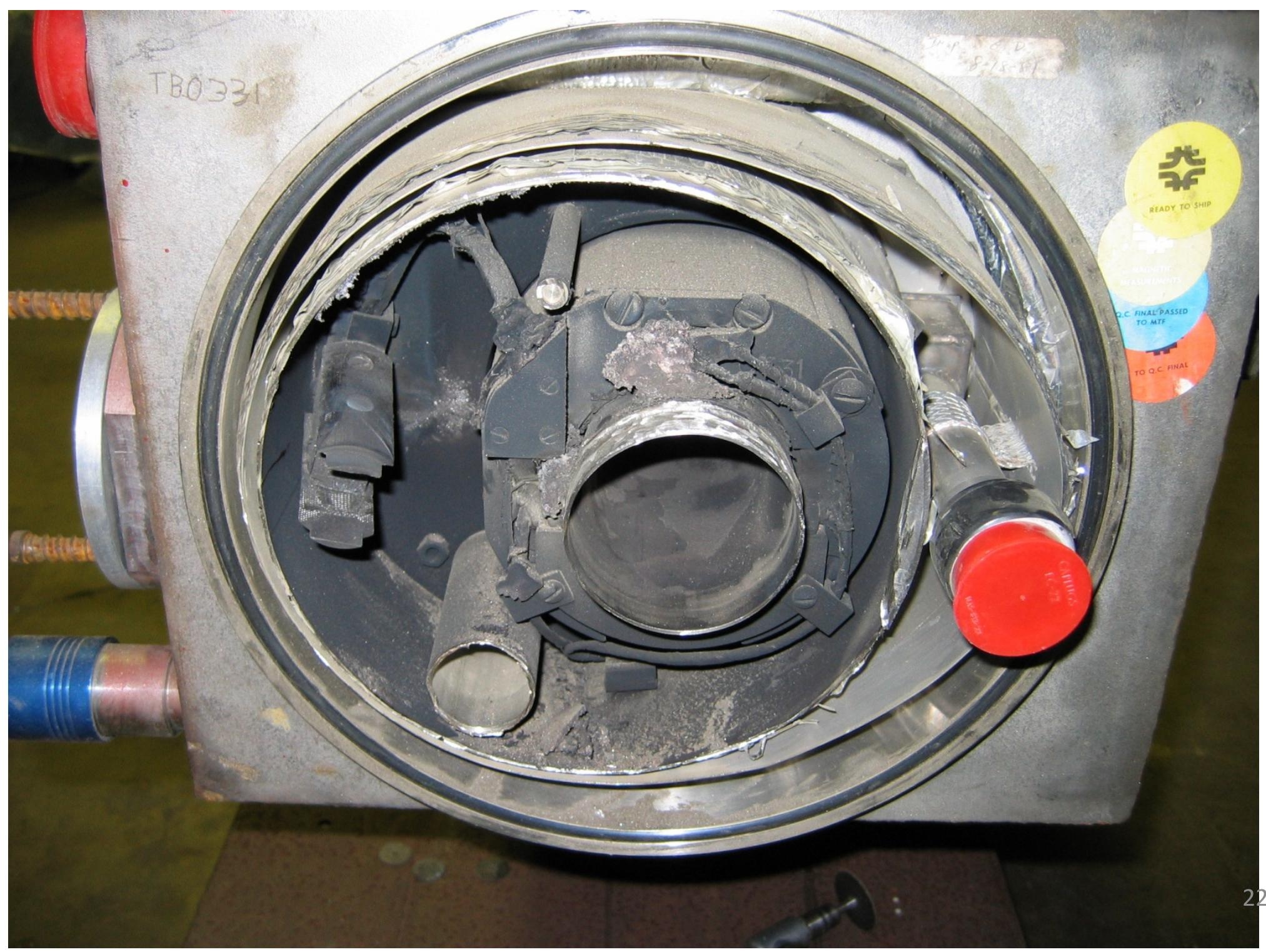




\section{View of beam tube}




\section{Equipment}

- Diffusion pump based leak detectors with upgraded electronics

- Electronic signal from all leak detectors fed to one custom computer (1 to 16 channel chart recorder lab view based)

- All signals can be analyzed at one time and compared to one another 


\section{Leak Detector}

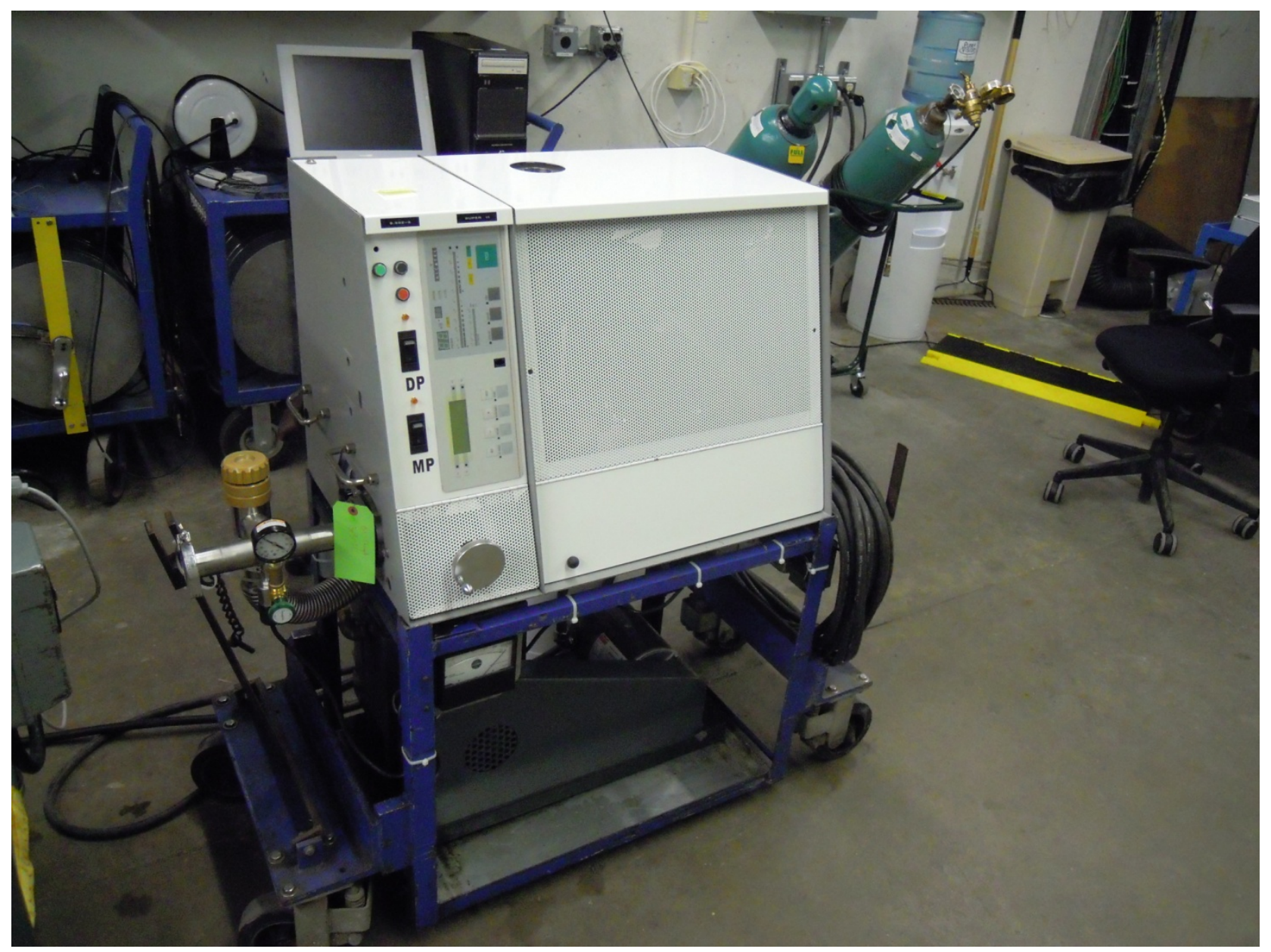




\section{Chart Recorder}

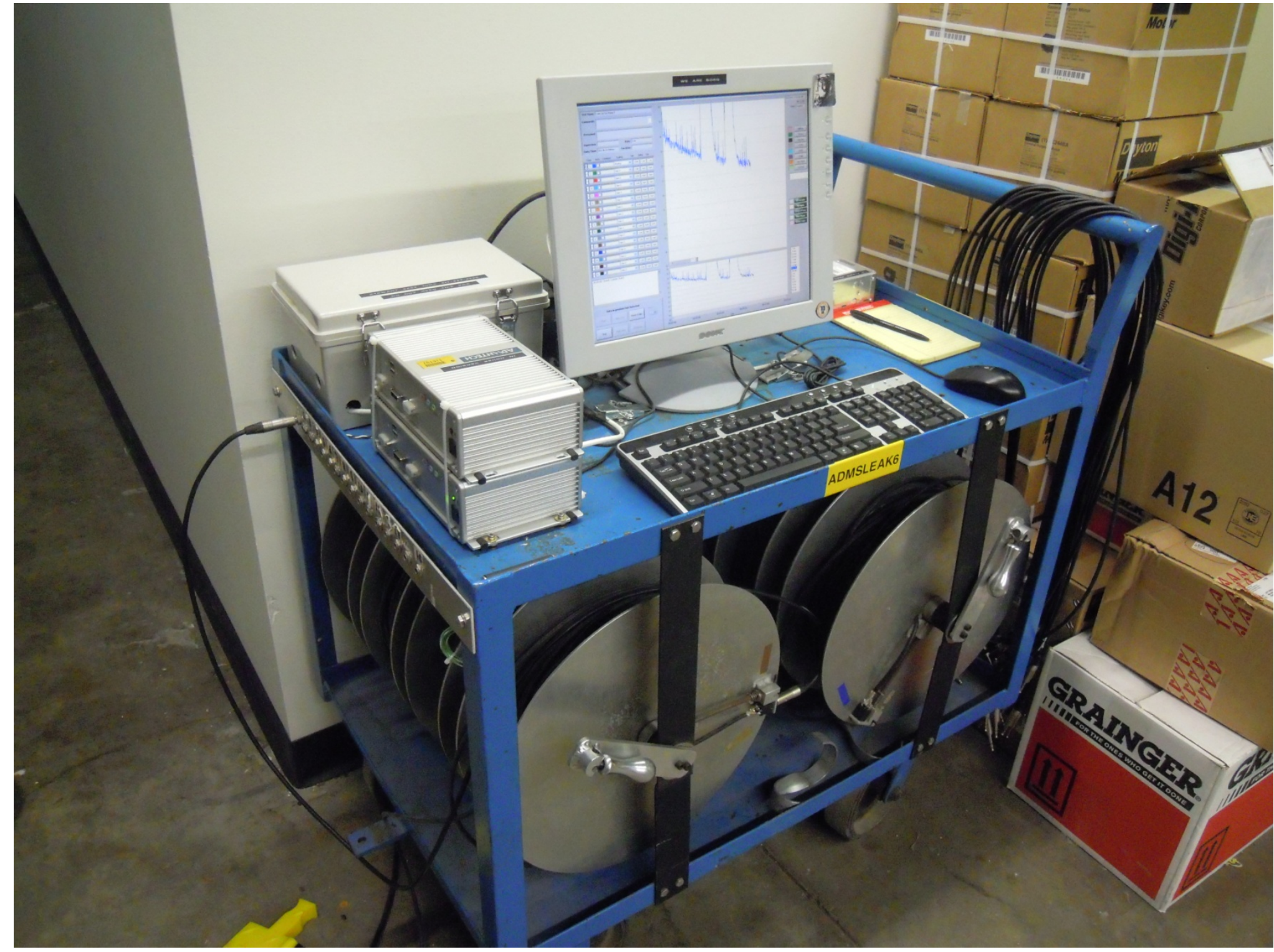




\section{Chart of test}

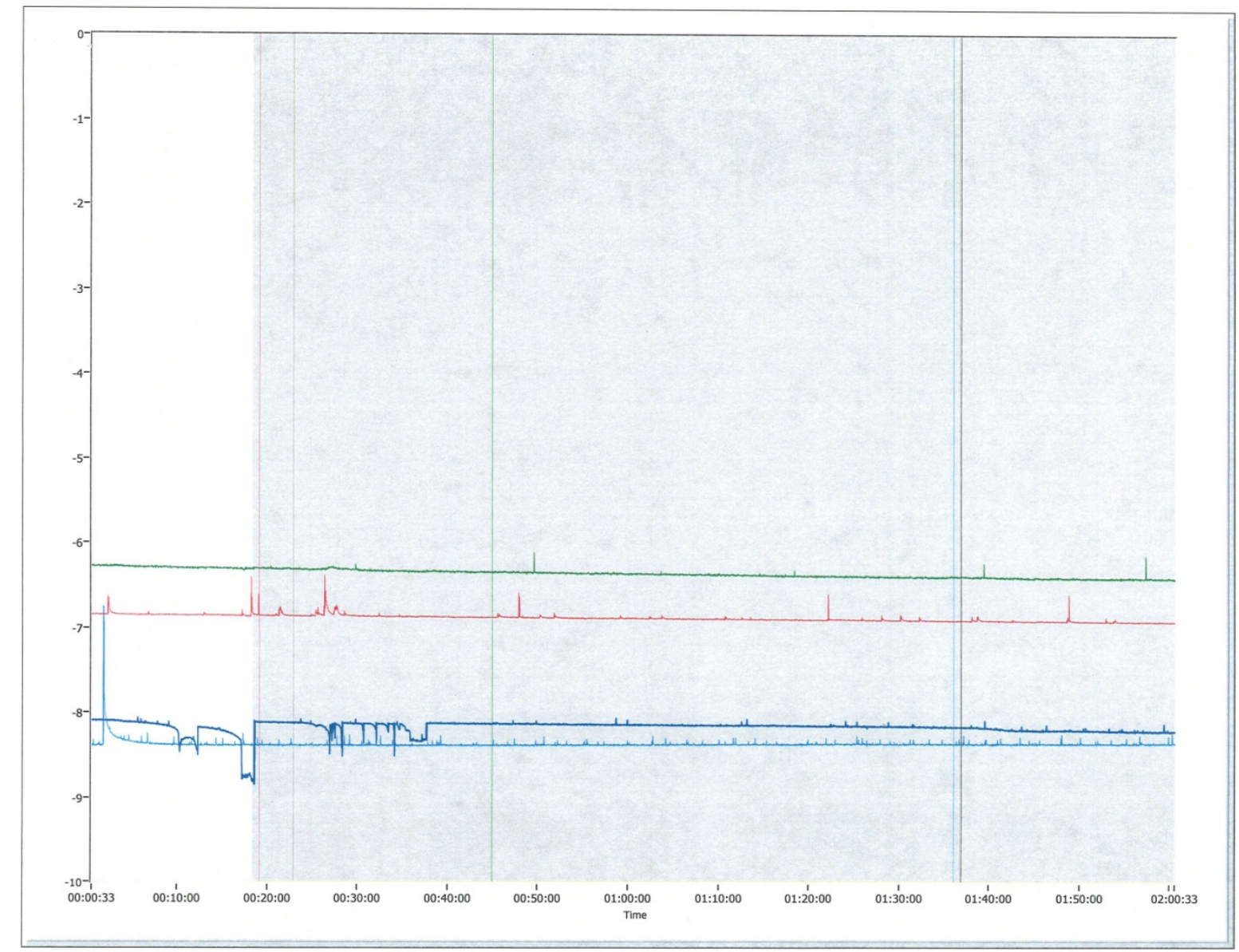




\section{Lessons Learned}

\section{O-rings}

Problem: original EPDM o-rings cleaned with acetone, causing o-ring to melt over time

Solution: switched to EPDM colorized series o-rings for easy identification to choose correct cleaning solvents

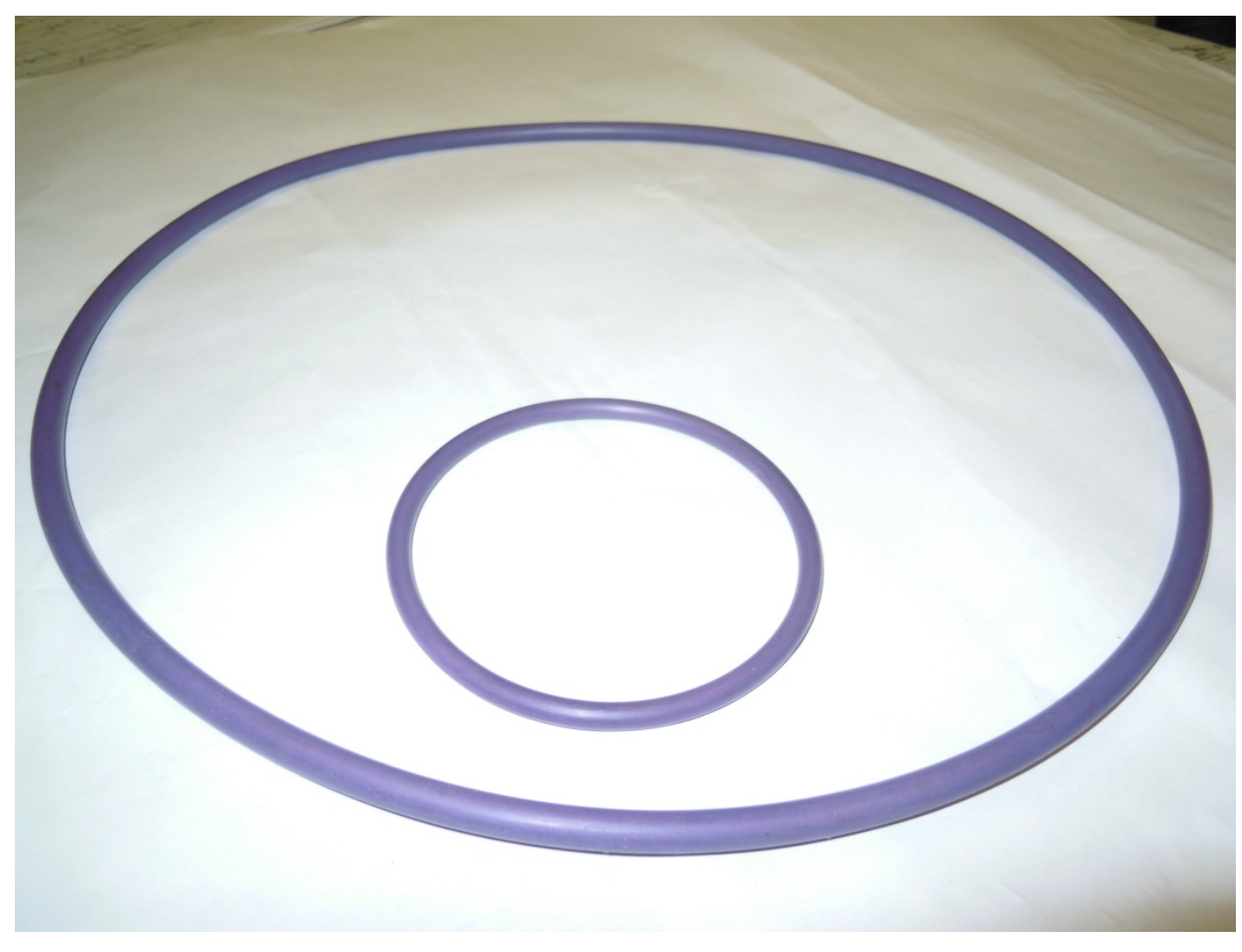




\section{The O-ring}

\section{fix continued}

It takes many hours

to disconnect,

replace and o-ring

We decided to

vulcanize a new o-

ring around the

interface saving 4

hours per interface

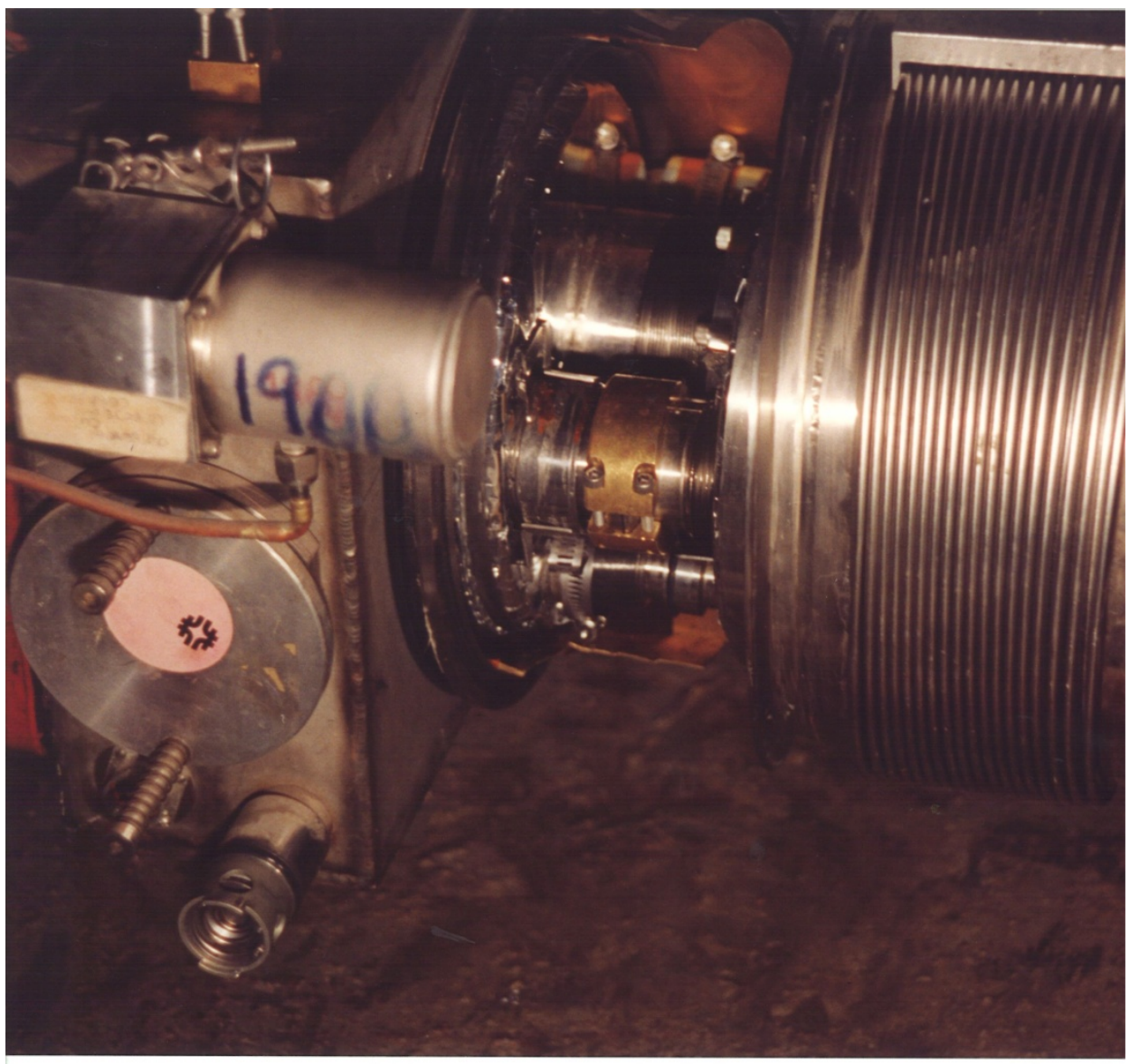




\section{The end of a great run}

- Collider run to end FY 2011

- Performance of collider chain was stellar

- The Tevatron will be warmed to room temp

- Much of the vacuum infrastructure will be used in future neutrino projects 


\section{Acknowledgements}

- This presentation was made possible by the gracious assistance of:

- Lucy Nobrega, Cryomodule Test Facility Vacuum Engineer

- Linda Valerio, Accelerator NuMI Upgrade Installation Engineer 